\title{
Backstepping based power control of a three-phase single-stage grid-connected PV system
}

\author{
M. El malah, A. Ba-razzouk, M. Guisser, E. Abdelmounim, M. Madark \\ Department of Applied Physics, ASTI Laboratory, FST Settat, University Hassan ${ }^{\text {st }}$ Settat, Morocco
}

\begin{tabular}{l}
\hline \hline Article Info \\
\hline Article history: \\
Received Aug 2, 2018 \\
Revised Apr 15, 2019 \\
Accepted Jun 26, 2019 \\
\hline Keywords: \\
Backstepping controller \\
Grid connection \\
Maximum power point tracking \\
PV systems \\
Unity power factor \\
\hline
\end{tabular}

\begin{abstract}
In order to reduce costs while maintaining superior performance, this paper presents a new control methodology of a three-phase grid connected photovoltaic system without using the intermediary DC/DC converter. Based on the synchronized nonlinear model of the whole photovoltaic system, two controllers have been proposed for the three-phase inverter in order to ensure the operation of the PV system at the maximum power point with unity power factor and minimum grid disturbance. Grid synchronization has been ensured by a three-phase $2^{\text {nd }}$ order PLL (Phase-Locked Loop). The stability of each controller is demonstrated by means of Lyapunov analysis and evaluated under changing atmospheric conditions using the Matlab/Simulink environment, the simulation results clearly demonstrate the performance provided by each controller.
\end{abstract}

Copyright $\odot 2019$ Institute of Advanced Engineering and Science. All rights reserved.

Corresponding Author:

Mohammed El malah,

Hassan $1^{\text {st }}$ University FST Settat, Settat, Morocco.

Email: medelmalah @gmail.com

\section{INTRODUCTION}

Nuclear energy is not likely to be a major source of world energy consumption because of the relative risks associated with unleashing the power of the atom and we have no choice but to invest heavily in renewable energy production. Solar energy is one of the most promising renewable electricity sources in the world. Moreover, the coordinated inter-connection of solar energy sources between global electricity markets can supply more flexibility and balancing to the grid. This is why the grid-connected photovoltaic systems have a great bright future.

Achieving the reduction of PV system manufacturing costs remains a major task. Among the trends to achieve such a reduction is the elimination of the DC/DC converter stage. Conventionally, the first converter stage, which is usually placed between the PV arrays and the inverter [1-3], achieves the MPPT whereas the inverter stage delivers and controls the energy injected into the grid. Therefore, to achieve this cost reduction, the three-phase inverter must also take care of the maximum power point tracking.

Maximum power point tracking is mandatory to maximize photovoltaic systems efficiency. To this end, several MPPT control strategies have been largely published in the last few years [1-13]. Perturb and observe (P\&O) and incremental conductance (IC) algorithms are the most widely proposed in literature. They are the simplest algorithms to implement [3-5], but the dilemma -the choice between convergence speed and output fluctuations [5, 6], has led in recent years to several research aimed at improving these two techniques [14-17]. The nonlinearity of photovoltaic characteristics makes the control of PV systems by conventional control strategies a complex task. However, the recent involvement of robust and nonlinear controls has enriched the field of research and has proved most appropriate for the control of nonlinear systems [7-12]. In particular, [6, 18] are comparative studies between the backstepping control and other conventional controls which clearly showed the performance of the backstepping control. 
In this paper, two controllers for the three-phase inverter, based on backstepping approach, are proposed and discussed. The first control objective is to track the maximum power point $\left(\partial \mathrm{P}_{\mathrm{p}} / \partial \mathrm{V}_{\mathrm{P}}=0\right)$. The second objective is to ensure a grid connection with unity power factor (output current must be in phase with the grid voltage). The proposed controllers are developed in the synchronous orthogonal frame and the voltage phase angle of the grid utility is detected using a three-phase PLL (Phase-Locked Loop).

This paper is organized as follows. In section two, the system description and the mathematical model are presented. Section three develops the control strategies of proposed system. Simulation results are presented and compared in section four. In the last section, a conclusion followed by the reference list.

\section{DESCRIPTIONS AND MODELING OF PV SYSTEM}

The PV cell is basically a p-n semiconductor junction that converts light energy into electrical energy. The PV cell can be represented by a current source controlled by voltage, sensitive to temperature and solar radiation, in parallel with one diode and a shunt resistor $R_{s h}$ and the whole is in series with a resistor $R_{s}$ as shown in Figure 1. Although it is a simplified model, this equivalent circuit is sufficiently accurate to represent the different types of photovoltaic cells [19]. The mathematical model of solar cells is detailed in [3].

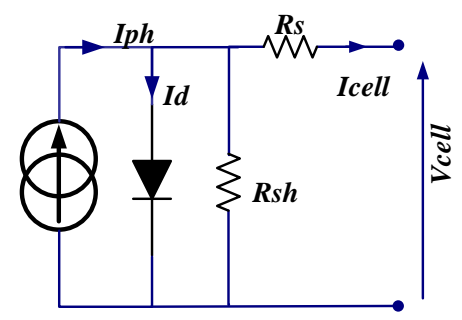

Figure 1. Equivalent circuit of PV cell

The photovoltaic array is a multiple associations, in series and parallel, of PV cells. The PV generator considered in this paper is composed by thirty-three SM55 Siemens panels connected in series. The electrical specifications for one panel are enlisted in Table 1. The modeling of the SM55 panel, using Matlab/Simulink, allowed tracing its characteristics for different values of irradiance and temperature which are shown in Figure 2 and Figure 3. Figure 4 shows the power-voltage characteristics of the PV generator considered in this paper under changing climatic conditions. The coordinates of the Maximum Power Points (MPP1, MPP2 and MPP3) summarized in Table 2 will be used for verification of the simulation results.

Table 1. Electrical specifications for SM55 solar panel

\begin{tabular}{cc}
\hline Parameter & Value \\
\hline Maximum power & $55 \mathrm{~W}$ \\
Current at the maximum power point & $3.15 \mathrm{~A}$ \\
Voltage at the maximum power point & $17.4 \mathrm{~V}$ \\
Maximum current (short circuit output) & $3.45 \mathrm{~A}$ \\
Maximum voltage (open circuit) & $21.7 \mathrm{~V}$ \\
Current temperature coefficient & $1.2 \mathrm{~mA} /{ }^{\circ} \mathrm{C}$ \\
Number of series cells Ns & 36 \\
Number of parallel modules Np & 1 \\
\hline
\end{tabular}

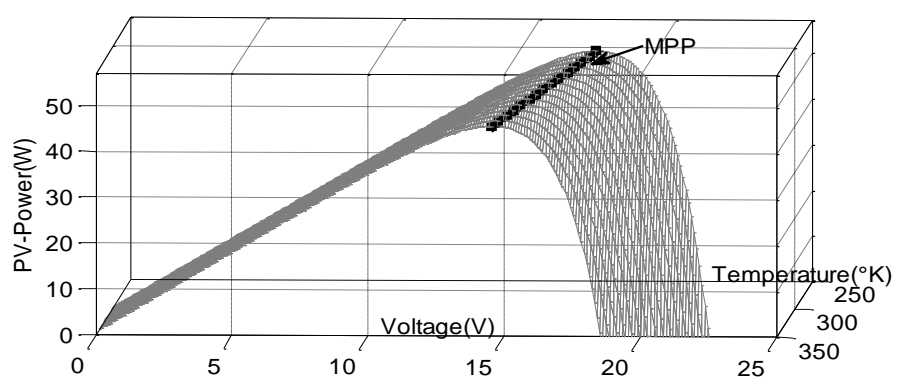

Figure 2. Power-voltage characteristics for the SM55 panel at $1000 \mathrm{~W} / \mathrm{m} 2$ with varying temperature levels

Backstepping based power control of a three-phase single-stage grid-connected PV system (M. El malah) 


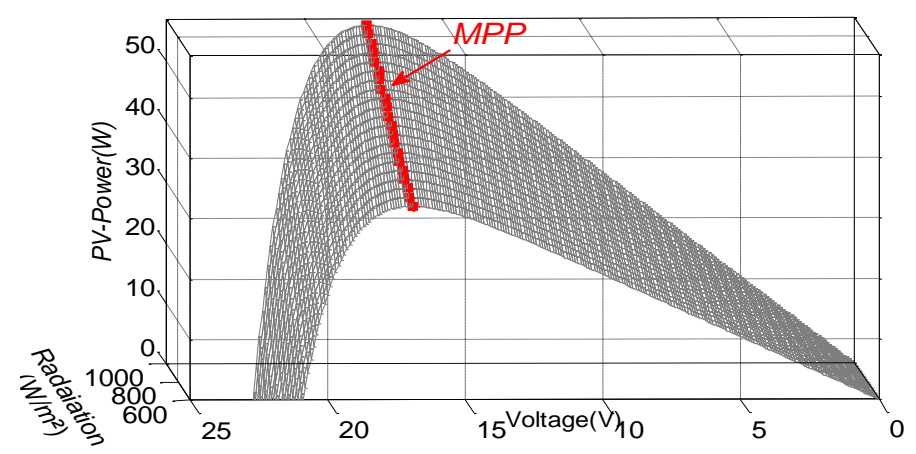

Figure 3. Power-voltage characteristics for the SM55 panel at 1000W/m2 with varying temperature levels

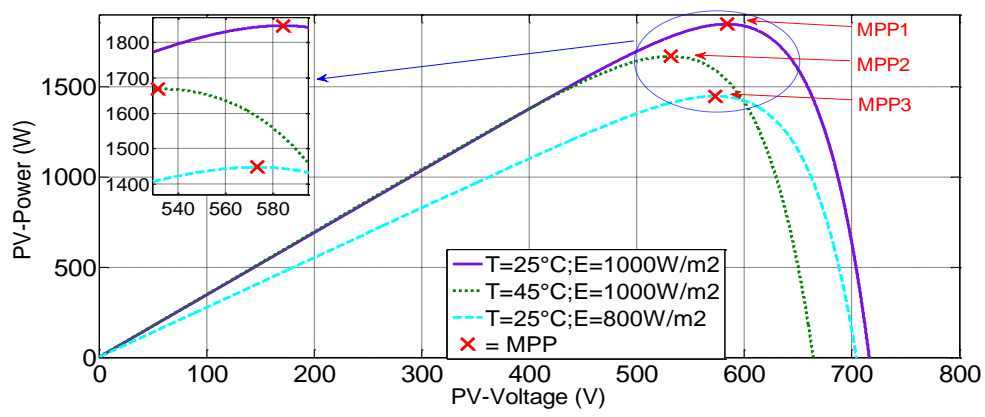

Figure 4. Power-voltage characteristics for the SM55 panel at $1000 \mathrm{~W} / \mathrm{m} 2$ with varying temperature levels

\begin{tabular}{ccc}
\multicolumn{3}{c}{ Table 2. Maximum power points (MPP) in Figure 4 } \\
\hline Maximum power point & Voltage[ V ] & Power [ W ] \\
\hline MPP1 & 584 & 1847 \\
MPP2 & 531.6 & 1669 \\
MPP3 & 573.2 & 1447.8 \\
\hline
\end{tabular}

The basic power circuit of proposed single stage PV-system as shown in Figure 5 consists of a DClink capacitor which is directly connected to the three-phase inverter. Grid connection was performed through a low-pass filter used to reduce the ripple components due to the switching actions in PWM inverter. It is assumed that all three phase inverter switches are ideal, the low-pass filter phases are identical and the grid voltage is symmetric. The three-phase model is detailed in [7]. A simplified model can be obtained in the synchronous frame rotating at the angular frequency of the grid voltage. For this purpose, the powerinvariant dq-transformation, from balanced three phase electrical quantities to balanced two phase quadrature quantities, has been used:

$$
\begin{aligned}
& {\left[\begin{array}{ll}
K_{d} & K_{q}
\end{array}\right]^{T}=T(\theta)\left[\begin{array}{lll}
k_{1} & k_{2} & k_{3}
\end{array}\right]^{T}} \\
& {\left[\begin{array}{ll}
I_{d} & I_{q}
\end{array}\right]^{T}=T(\theta)\left[\begin{array}{lll}
i_{1} & i_{2} & i_{3}
\end{array}\right]^{T}} \\
& {\left[\begin{array}{ll}
E_{d} & E_{q}
\end{array}\right]^{T}=T(\theta)\left[\begin{array}{lll}
e_{1} & e_{2} & e_{3}
\end{array}\right]^{T}}
\end{aligned}
$$

and

$$
T(\theta)=\sqrt{\frac{2}{3}}\left[\begin{array}{ccc}
\cos (\theta) & \cos \left(\theta-\frac{2 \pi}{3}\right) & \cos \left(\theta+\frac{2 \pi}{3}\right) \\
-\sin (\theta) & -\sin \left(\theta-\frac{2 \pi}{3}\right) & -\sin \left(\theta+\frac{2 \pi}{3}\right)
\end{array}\right]
$$

where $\left(k_{1} ; k_{2} ; k_{3}\right)$ : Inverter control inputs; $\left(i_{1} ; i_{2} ; i_{3}\right)$ : Injected currents $\left(e_{1} ; e_{2} ; e_{3}\right)$ : Grid voltages, and $\theta$ is the angular position of the dq- frame. The state-space model can be re-written in the new frame, as ([7]): 


$$
\left\{\begin{array}{l}
\frac{d I_{d}}{d t}=\frac{-R}{L} I_{d}+\omega I_{q}-\frac{E_{d}}{L}+\frac{V_{p}}{L} K_{d} \\
\frac{d I_{q}}{d t}=-\omega I_{d}+\frac{-R}{L} I_{q}-\frac{E_{q}}{L}+\frac{V_{p}}{L} K_{q} \\
\frac{d V_{p}}{d t}=\frac{1}{C}\left(I_{p}-I_{d} K_{d}-I_{q} K_{q}\right)
\end{array}\right.
$$

where $I_{p} ; V_{p}:$ Are the PV array current and voltage

\section{CONTROLLER DESIGN}

The injected currents have to be synchronized with the grid voltages. To this end, the grid voltage phase angle is detected using a 2nd order phase locked loop (PLL). The structure of the PLL implemented in this work as shown in Figure 6 uses the grid voltage abc-dq transformation to track the grid voltages phase angle. A PI regulator was used to generate a corrective phase angle ( $\theta$ est), that is fed back into the grid voltage abc-dq transformation module, from the quadrature voltage error [20]. The three-phase grid currents and voltages are transformed into direct and quadrature axis components, the controller outputs $\left(K_{d} \& K_{q}\right)$ are then transformed into three-phase components using the inverse dq-abc transformation, and then a PWM control is used to make them suitable for switching the inverter switches as shown in Figure 5.

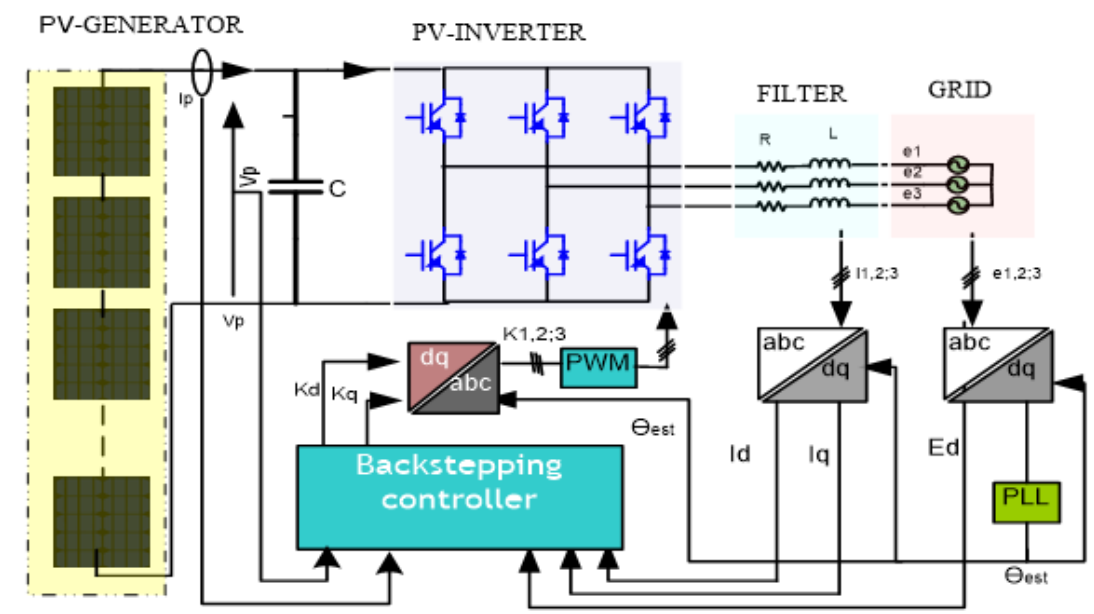

Figure 5. Control scheme of the proposed photovoltaic system

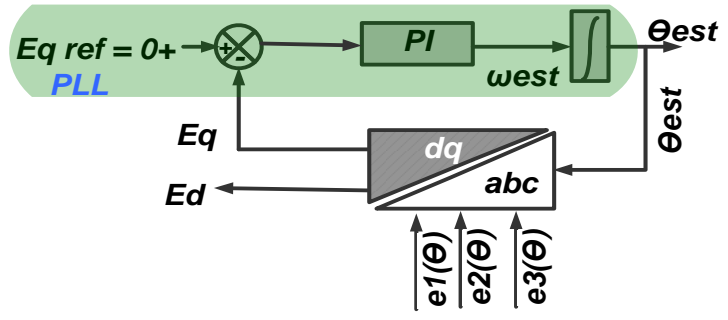

Figure 6. Basic principle of PLL

In the synchronous d-q reference frame $\left(E_{q}=0\right)$, the injected powers are simplified, the active and reactive powers can be controlled by $I_{d}$ and $I_{q}$ respectively:

$$
\left\{\begin{array} { l } 
{ P = E _ { d } I _ { d } + E _ { q } I _ { q } } \\
{ Q = E _ { q } I _ { d } - E _ { d } I _ { q } }
\end{array} \quad \Longrightarrow \quad \left\{\begin{array}{l}
P=E_{d} I_{d} \\
Q=-E_{d} I_{q}
\end{array}\right.\right.
$$


In order to achieve a minimum injection of reactive power the quadrature current reference $I_{\text {qref }}$ must be set to zero. If we neglect ohmic loss, the power conservation principle gives:

$$
I_{\text {dref }}=\frac{V_{p} I_{p}}{E_{d}}=\frac{P_{p}}{E_{d}}
$$

Finally, when the PV-generator power is at its maximum state, Figure 3, its derivative with respect to PV-voltage is zero. Table 3 summarizes the selected dynamic outputs and their references for each controller.

Table 3. Dynamic outputs and their references

\begin{tabular}{ccc}
\hline & The dynamic output considered & Output Reference \\
\hline First Backstepping Controller & $y=\left[\begin{array}{l}y_{1} \\
y_{2}\end{array}\right]=\left[\begin{array}{c}\frac{\partial P_{p}}{\partial V_{p}} \\
e_{d}{ }^{2}+e_{q}{ }^{2}\end{array}\right]$ & $y_{\text {ref }}=\left[\begin{array}{c}\left(\frac{\partial P_{p}}{\partial V_{p}}\right)_{r e f} \\
\left(e_{d}{ }^{2}+e_{q}{ }^{2}\right)_{r e f}\end{array}\right]=\left[\begin{array}{l}0 \\
0\end{array}\right]$ \\
Second Backstepping Controller & $y=\left[\begin{array}{l}y_{1} \\
y_{2}\end{array}\right]=\left[\begin{array}{c}\frac{\partial P_{p}}{\partial V_{p}} \\
I_{q}\end{array}\right]$ & $y_{\text {ref }}=\left[\begin{array}{c}\left(\frac{\partial P_{p}}{\partial V_{p}}\right)_{r e f} \\
I_{q_{r e f}}\end{array}\right]=\left[\begin{array}{l}0 \\
0\end{array}\right]$ \\
\hline
\end{tabular}

where: $e_{d}=I_{d}-I_{d r e f}$ is the direct current error, $e_{q}=I_{q}-I_{\text {qref }}$ is the quadrature current error.

The output chosen for the second controller is simpler than the first, but it is a challenging and time-consuming task to tune the appropriate backstepping parameters in this controller. This is largely due to the fact that establishing stability for switched systems is difficult. Therefore, in the first controller, we have chosen to also involve the direct current component $I_{d}$ in the control of the output power.

\subsection{Formulation of MPPT control law (controller 1\&2)}

Let us define the first tracking error $\epsilon_{1}$ and its LFC (Lyapunov Function Candidate) $V_{1}$, using (2), it is possible to deduce:

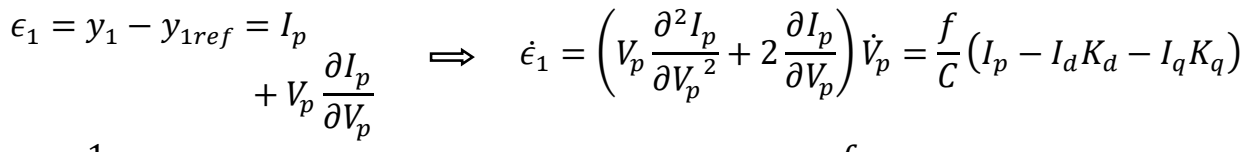

$$
\begin{aligned}
& V_{1}=\frac{1}{2} \epsilon_{1}{ }^{2} \quad \Rightarrow \quad \dot{V}_{1}=\epsilon_{1} \dot{\epsilon}_{1}=\frac{\epsilon_{1} f}{C}\left(I_{p}-I_{d} K_{d}-I_{q} K_{q}\right)
\end{aligned}
$$

The stabilizing controls $K_{d}$ and $K_{q}$ is chosen as follows:

$$
B_{1}+A_{1} K_{d}+A_{2} K_{q}=0 \quad \text { where }\left\{\begin{array}{c}
B_{1}=\frac{I_{p} f}{C}+c_{1} \epsilon_{1} ; A_{1}=\frac{-I_{d} \cdot f}{C} ; A_{2}=\frac{-I_{q} \cdot f}{C} \\
f=V_{p} \frac{\partial^{2} I_{p}}{\partial V_{p}{ }^{2}}+2 \frac{\partial I_{p}}{\partial V_{p}} \text { and } c_{1} \text { is a positive parameter }
\end{array}\right.
$$

With the above choice $\dot{V}_{1}=-c_{1} \epsilon_{1}^{2}$ becomes defined negative, $\epsilon_{1}$ is proved to be asymptotically stable and converge to zero by the Lyapunov design. This means that $y_{1} \rightarrow y_{1 r e f}$, so $P_{p} \rightarrow\left(P_{p}\right)_{M P P}$.

\subsection{Formulation of output power control law}

\subsubsection{First controller}

According to Table 3 we define the error $\epsilon_{2}$ and its derivative, deduced from (2), as follows:

$$
\left\{\begin{array}{l}
\epsilon_{2}=y_{2}-y_{2 \text { ref }} \\
\dot{\epsilon}_{2}=2 e_{d}\left(\frac{-R}{L} I_{d}+\omega I_{q}-\frac{E_{d}}{L}+\frac{V p}{L} K_{d}-\dot{I}_{d r e f}\right)+2 e_{q}\left(-\omega I_{d}+\frac{-R}{L} I_{q}+\frac{V p}{L} K_{q}\right) \\
\text { where: } \quad \dot{I}_{d r e f}=\frac{\dot{P}_{p}}{E_{d}}=\frac{\epsilon_{1}}{E_{d}} \dot{V}_{p}=\frac{\epsilon_{1}}{E_{d} C}\left(I_{p}-I_{d} K_{d}-I_{q} K_{q}\right)
\end{array}\right.
$$


Let us consider the following new LFC, its derivative is deduced frome (8) as follows:

$$
\left\{\begin{array}{l}
V_{2}=V_{1}+\frac{1}{2} \epsilon_{2}^{2} \\
\dot{V}_{2}=-c_{1} \epsilon_{1}^{2}+2 \epsilon_{2}\left[e_{d}\left(\frac{-R}{L} I_{d}+\omega I_{q}-\frac{E_{d}}{L}+\frac{V p}{L} K_{d}-\dot{I}_{d r e f}\right)+e_{q}\left(-\omega I_{d}+\frac{-R}{L} I_{q}+\frac{V p}{L} K_{q}\right)\right]
\end{array}\right.
$$

Then the stabilizing controls $\left(K_{d}\right.$ and $\left.K_{q}\right)$ is chosen as follows:

$B_{2}+A_{3} K_{d}+A_{4} K_{q}=0\left\{\begin{array}{l}B_{2}=\frac{1}{2} c_{2} \epsilon_{2}+e_{d}\left(\frac{-R}{L} I_{d}+\omega I_{q}-\frac{E_{d}}{L}-\frac{\epsilon_{1}}{E_{d} C} I_{p}\right)+e_{q}\left(-\omega I_{d}-\frac{R}{L} I_{q}\right) \\ A_{3}=e_{d} \frac{V p}{L}+\frac{\epsilon_{1} e_{d}}{E_{d} C} I_{d} ; A_{4}=e_{q} \frac{V p}{L}+\frac{\epsilon_{1} e_{d}}{E_{d} C} I_{q} ; c_{2} \text { is a positive parameter. }\end{array}\right.$

With the above choice $\dot{V}_{2}=-c_{1} \epsilon_{1}^{2}-c_{2} \epsilon_{2}^{2}<0, \epsilon_{1}$ and $\epsilon_{2}$ are proved to be stable and converge to zero by the Lyapunov design. This means that $y$ converge to $y_{\text {ref }}$. We are finally in a position to determine the control signals $K_{d} \& K_{q}$. From (7) and (10), we deduce (11):

$$
\left[\begin{array}{ll}
A_{1} & A_{2} \\
A_{3} & A_{4}
\end{array}\right]\left[\begin{array}{l}
K_{d} \\
K_{q}
\end{array}\right]=-\left[\begin{array}{l}
B_{1}^{2} \text {.2.1.S } \\
B_{2}
\end{array}\right] \mathbf{e} \quad \Longrightarrow \quad\left[\begin{array}{l}
K_{d} \\
K_{q}
\end{array}\right]=-\left[\begin{array}{ll}
A_{1} & A_{2} \\
A_{3} & A_{4}
\end{array}\right]^{-1}\left[\begin{array}{l}
B_{1} \\
B_{2}
\end{array}\right]
$$

\subsubsection{Second controller}

The tracking error $\epsilon_{2}$ is reduced to (12):

$$
\epsilon_{2}=I_{q}-I_{\text {qref }}=I_{q} \stackrel{\text { From (2) }}{=} \quad \dot{\epsilon}_{2}=-\omega I_{d}+\frac{-R}{L} I_{q}-\frac{E_{q}}{L}+\frac{V p}{L} K_{q}
$$

and the control low $K_{q}$ can be extracted directly from the second equation of mathematical model (2), by choosing $K_{d}$ such that:

$$
K_{q}=\frac{L}{V p}\left(-c_{2} I_{q}+\omega I_{d}+\frac{R}{L} I_{q}\right) \Rightarrow \dot{\epsilon}_{2}=-c_{2} \epsilon_{2} \Rightarrow \dot{V}_{2}=\dot{V}_{1}+\epsilon_{2} \dot{\epsilon}_{2}=-c_{1} \epsilon_{1}^{2}-c_{2} \epsilon_{2}^{2}
$$

Using (7) and (13), we obtain the control signals (14):

$$
\left[\begin{array}{l}
K_{d} \\
K_{q}
\end{array}\right]=-\left[\begin{array}{cc}
A_{1} & A_{2} \\
0 & \frac{V p}{L}
\end{array}\right]^{-1}\left[\begin{array}{c}
B_{1} \\
c_{2} I_{q}-\omega I_{d}-\frac{R}{L} I_{q}
\end{array}\right]
$$

\section{SIMULATION RESULTS}

The theoretical performances of the proposed controllers discussed in section three will be illustrated by simulation in this section. The PV system as shown in Figure 5 is simulated jointly with each controller, using the instantaneous three phase model, in Matlab/Simulink environment as shown in Figure 7. The model in $d-q$ axis (2) is only used in the controllers design. Important simulation parameters are given in the Table 4. Controllers' parameters have been selected using a 'trial-and-error' search method. In order to prove the robustness of the control algorithms, the simulation is performed with the following scenario:

a. A temperature increase from $\mathrm{T}=25^{\circ} \mathrm{C}(298.15 \mathrm{~K})$ to $\mathrm{T}=45^{\circ} \mathrm{C}(318.15 \mathrm{~K})$ after $1 \mathrm{sec}$ of start of simulation, then returns to $\mathrm{T}=25^{\circ} \mathrm{C}$ at $1.6 \mathrm{sec}$, as shown in Figure 8 .

b. A solar irradiation drop from $1000 \mathrm{~W} / \mathrm{m}^{2}$ to $800 \mathrm{~W} / \mathrm{m}^{2}$ after $0.4 \mathrm{sec}$ of start of simulation, then returns to $1000 \mathrm{~W} / \mathrm{m}^{2}$ at $0.3 \mathrm{~s}$ as shown in Figure 9.

Table 4. Characteristics of controlled photovoltaic system

\begin{tabular}{ccc}
\hline Parameter & Symbol & Value \\
\hline PV-array power & Pp & $1847 \mathrm{~W}$ \\
DC bus capacitor & $\mathrm{C}$ & $100 \mu \mathrm{F}$ \\
Switching frequency & $\mathrm{Fs}$ & $10 \mathrm{kHz}$ \\
AC source & $\mathrm{Vg}$ & $110 \mathrm{~V}$ \\
Line frequency & $\mathrm{f}$ & $50 \mathrm{~Hz}$ \\
Filter parameters & $\mathrm{L}$ & $12.5 \mathrm{mH}$ \\
& $\mathrm{R}$ & $0.5655 \Omega$ \\
controller parameters & $\boldsymbol{c}_{\mathbf{1}}$ & ${\mathbf{8} \times \mathbf{1 0}^{\mathbf{4}}}$ \\
& $\boldsymbol{c}_{\mathbf{2}}$ & $\mathbf{9 , 7} \times \mathbf{1 0}^{\mathbf{4}}$ \\
\hline
\end{tabular}




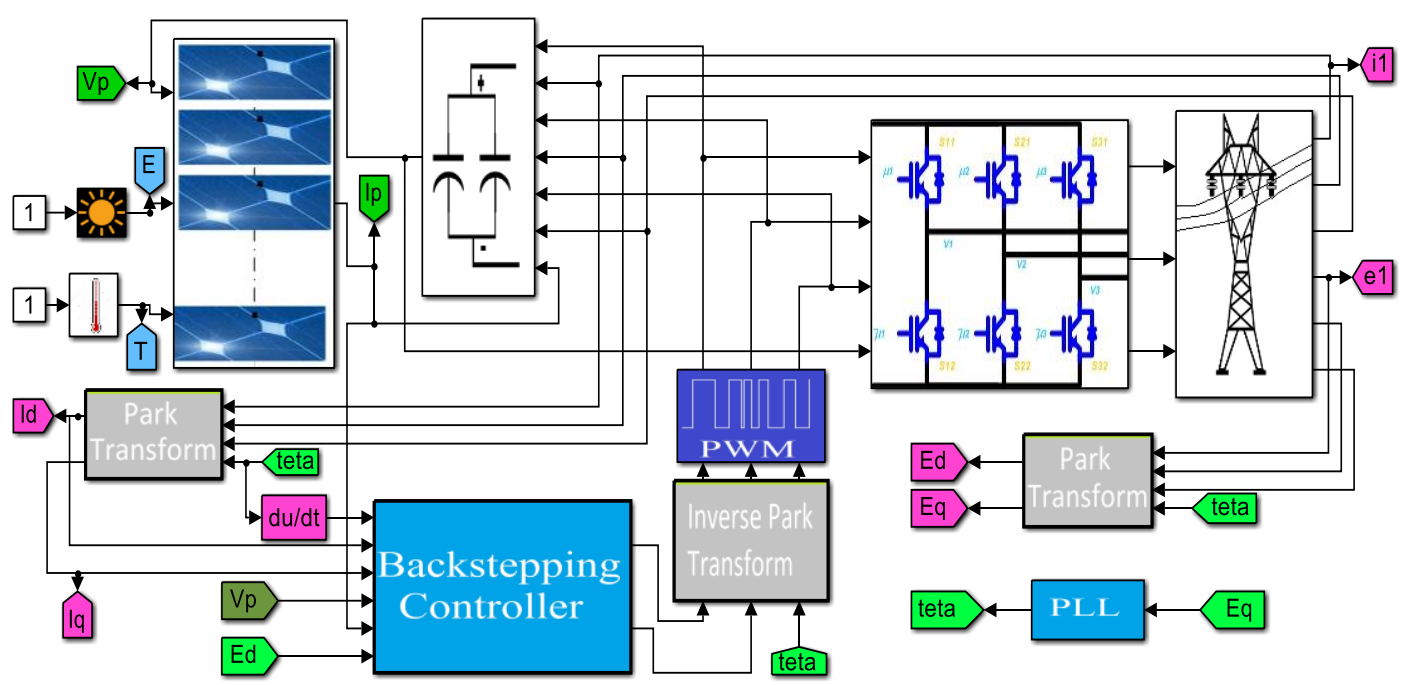

Figure 7. Simulation schema for the proposed PV system

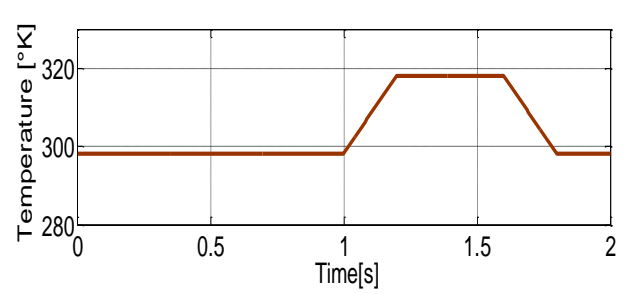

Figure 8. Temperature changes

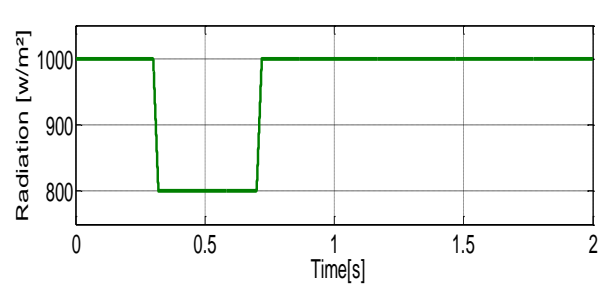

Figure 9. Irradiation changes

The first and second controllers are based respectively on (11) and (14), and use the same backstepping parameters as shown in Table 4. Simulation results of the PV array power and voltage under transient condition are shown in Figure 10, which correspond very well to the MPP coordinates summarized in Table 2.

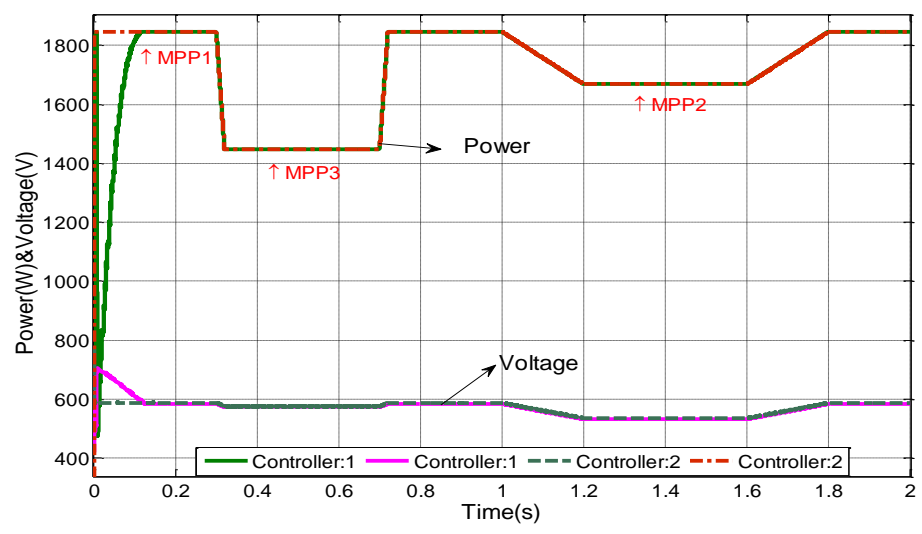

Figure 10. PV power and DC-bus voltage behaviors

Figure 11 illustrates the change of direct and quadrature current components. It can be clearly seen that the second controller can track the reference values with a fast transient response, but the first controller is the most accurate and the least disruptive of the grid. Figure 12 shows the grid voltage and the injected 
current obtained with each one of the proposed controllers (the grid current scale was multiplied by 10). It can easily be seen in the zoomed portions as shown in Figure 13 that the grid current is sinusoidal and in phase with the grid voltage which proving that the power factor unit is well achieved.

Remark: It should be noted that it is very difficult to tune backstepping parameters of the second controller to establish the stability, unlike the first controller whose parameters influence precisely on the precision and settling time.

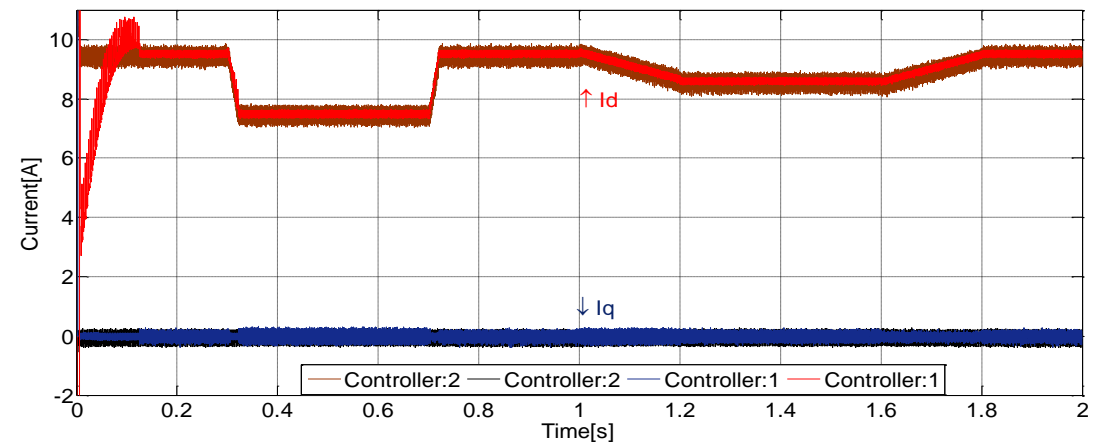

Figure 11. Current components behavior
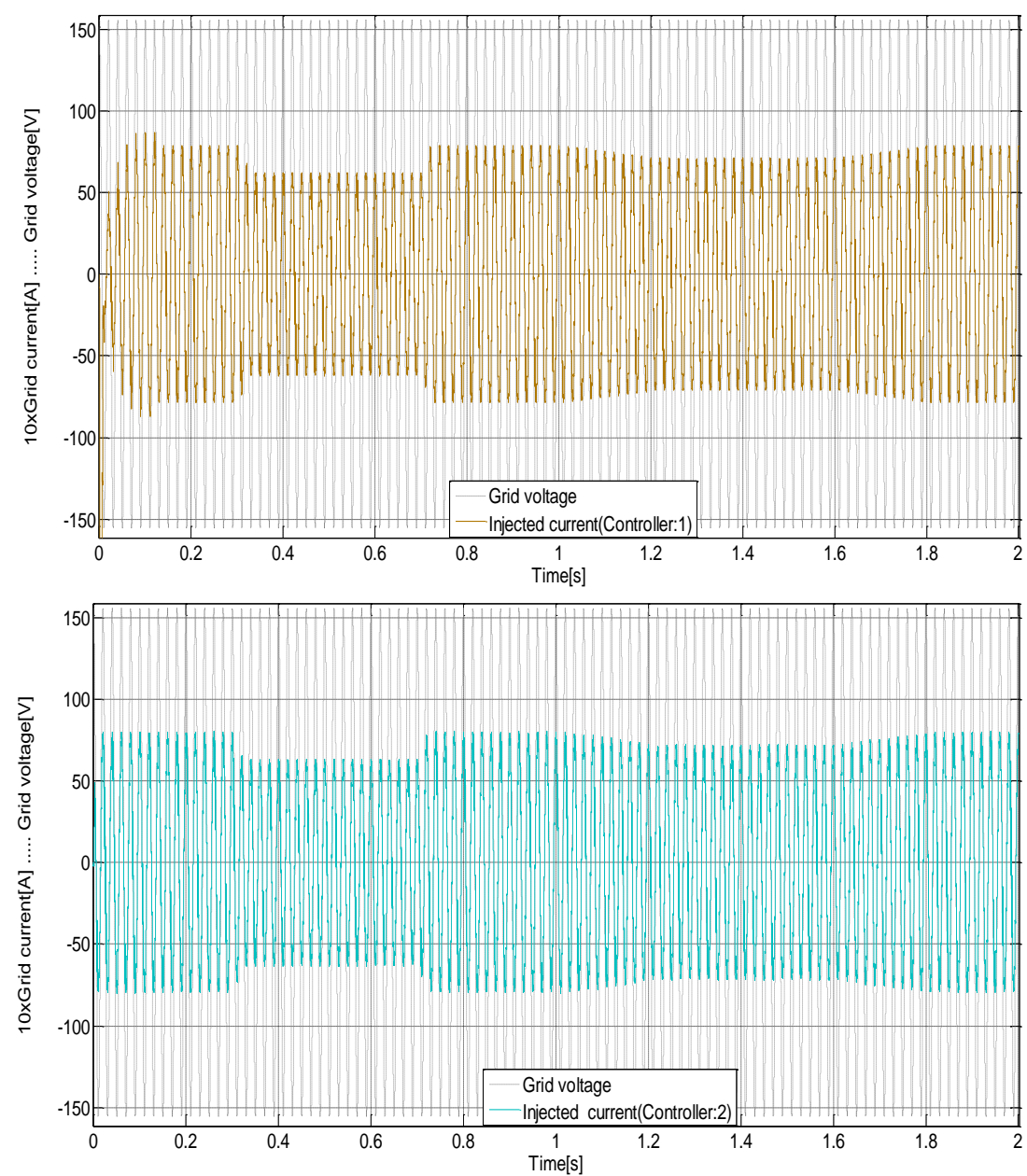

Figure 12. Voltage and the injected current of one phase 

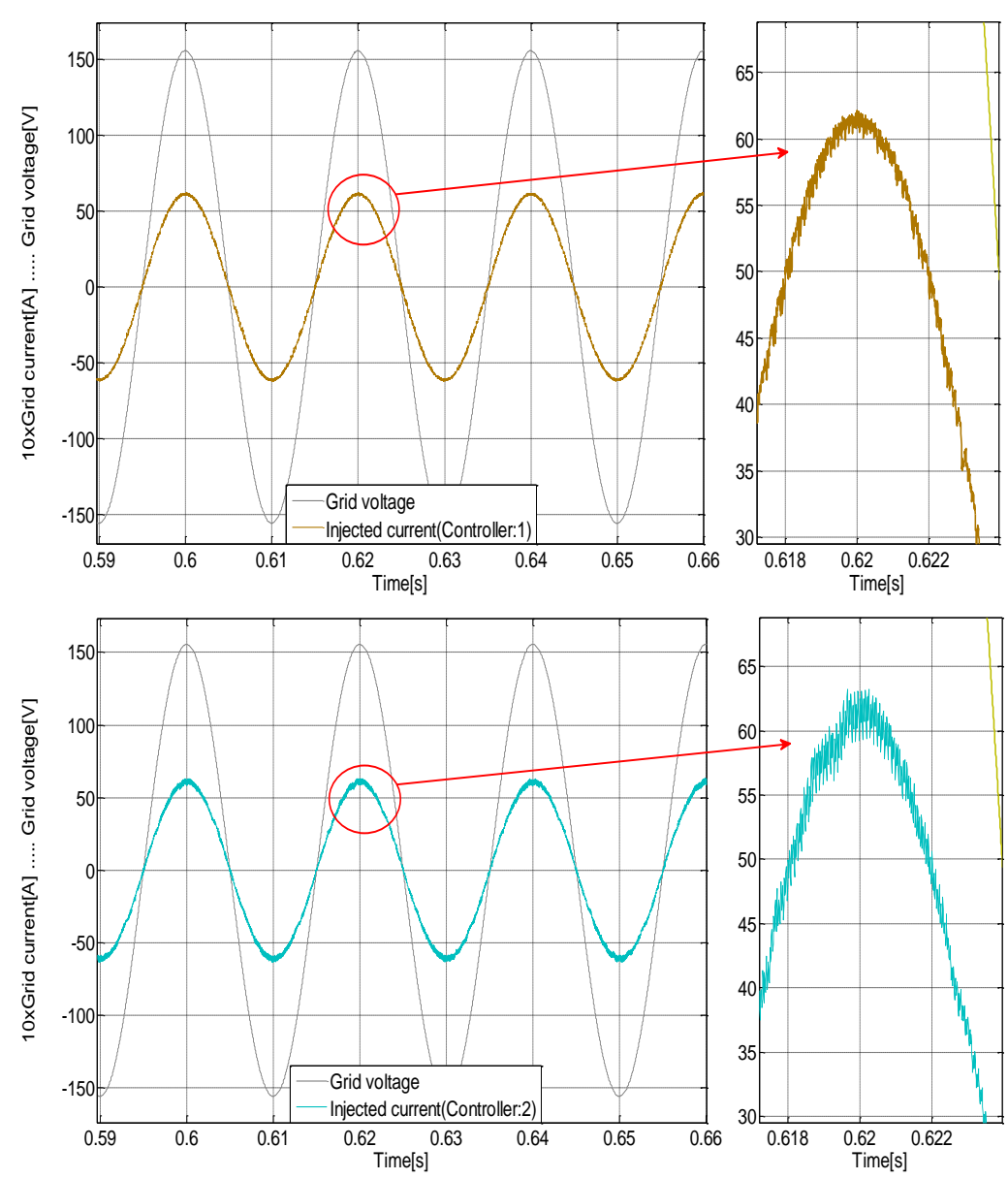

Figure 13. Zoomed portions of Figure 12

\section{CONCLUSION}

In this paper, two Backstepping controllers have been developed for a three phase single stage grid connected photovoltaic system, without using the conventional DC/DC converter for MPPT control, in order to ensure the operation of the PV system at maximum power point with unity power factor. From the simulation results, it has been proven that both algorithms, although they require more computation, are able to work under various levels of irradiation and temperature, it has also been deduced that the correct selection of system outputs helps to facilitate control tasks. Although the current of the first controller has fewer ripples compared to the second, the future work will deal with the mitigation of switching noise and the practical implementation.

\section{REFERENCES}

[1] O. Khan; W. Xiao, "An Efficient Modeling Technique to Simulate and Control Submodule-Integrated PV System for Single-Phase Grid Connection," IEEE Transactions on Sustainable Energy, vol. 7, pp. 96-107, Jan 2016.

[2] H. Bahri, M. Aboulfatah, M. Guisser, E. Abdelmounim, and M. El Malah, "Integral Backstepping Control for Maximum Power Point Tracking and Unity Power Factor of a Three Phase Grid Connected Photovoltaic System," International Journal of Electrical and Computer Engineering (IJECE), vol. 7 no. 4, pp. 1671-1680, Aug 2017.

[3] M. Louzazni, E. Aroudam, H. Yatimi, "Modeling and Simulation of A Solar Power Source for a Clean Energy without Pollution," International Journal Of Electrical And Computer Engineering, vol. 3, pp. 568-576, Aug 2017.

[4] M. Munir, T. Aldhanhani, K. Al Hosani, "Control of Grid Connected PV Array Using P\&O MPPT Algorithm," in Green Technologies Conference, 2017. GreenTech 2017. Ninth Annual IEEE, pp. 52-58, 2017.

[5] A. Harrag, A. Titraoui, H. Bahri, "P\&O or IC for PV pumping system: What MPPT algorithm to improve performances?," On Systems and Control, ICSC 2017. 6Th International Conference, 2017, pp. 220-225.

[6] Ankur, Sandipan Patra, Soumya R. Mohanty, Nand Kishor, "Maximum power point tracking of PV system with backstepping control," IEEE Students Conference on Engineering and Systems, SCES 2013, pp. 1-5, 2013. 
[7] M. El Malah, A. Ba-razzouk, M. Guisser, E. Abdelmounim, M. Madark, H. Bahri, "Nonlinear Predictive Control for Maximum Power Point Tracking and Unity Power Factor of a Three Phase Grid Connected PV System," International Review of Automatic Control (IREACO), vol. 11, pp. 133-142, 2018.

[8] D. Gonzalez Montoya, C. Andres Ramos-Paja, R. Giral, "Improved Design of Sliding-Mode Controllers Based on the Requirements of MPPT Techniques," IEEE Transactions on Power Electronics, vol. 31, pp. 235-247, Jan 2016.

[9] A. Boucetta, D. Labed, "Control of Power and Voltage of Solar Grid Connected," International Journal of Electrical and Computer Engineering (IJECE), vol. 6, no. 1, pp. 26-33, Feb 2016.

[10] M. Madark, A. Ba-razzouk, E. Abdelmounim, M. El Malah, "Backstepping with Integral Action Controller for a Solar Photovoltaic Powered Induction Motor," REPS-GIE 2018. Renewable Energies, Power Systems \& Green Inclusive Economy, pp. 1-6, 2018.

[11] A. Saudi Samosir, H. Gusmedi, S. Purwiyanti, E. Komalasari, "Modeling and Simulation of Fuzzy Logic based Maximum Power Point Tracking (MPPT) for PV Application," International Journal of Electrical and Computer Engineering (IJECE), vol. 8, no. 3, pp. 1315-1323, Jun 2018.

[12] D. Mlakić, L. Majdandžić, S. Nikolovski, "ANFIS used as a Maximum Power Point Tracking Algorithm for a Photovoltaic System," International Journal of Electrical and Computer Engineering (IJECE), vol. 8, no. 2, pp. 867-879, Apr 2018.

[13] P. Sudwilai, "A Design and Development of P I Controlled Based MPPT for Photovoltaic Systems," ICEMS 2018. 21 st International Conference on Electrical Machines and Systems, pp. 992-995, 2018.

[14] R. Alik, A. Jusoh, T. Sutikno, "A Study of Shading Effect on Photovoltaic Modules with Proposed P\&O Checking Algorithm," International Journal of Electrical and Computer Engineering (IJECE), vol. 7, no. 1, pp. 29-40, Feb 2017.

[15] Doaa M. Atia, Hanaa T. El-madany, "VHDL Based Maximum Power Point Tracking of Photovoltaic Using Fuzzy Logic Control," International Journal of Electrical and Computer Engineering (IJECE), vol. 7, no. 6, pp. 3454-3466, Dec 2017.

[16] A. Fri, R. El Bachtiri, A. El Ghzizal, "Improved MPPT Algorithm for Controlling a PV System Grid Connected for Rapid Changes of Irradiance," International Review of Automatic Control (IREACO), vol. 9, pp.11-20, 2016.

[17] E. Anto, J. Asumadu, P. Okyere, "PID control for improving P\&O-MPPT performance of a grid-connected solar PV system with Ziegler-Nichols tuning method," On Industrial Electronics and Applications, 2016. ICIEA 2016. IEEE 11Th Conference, pp. 1847-1852, 2016.

[18] R. Sureshkumar, S. Ganeshkumar, "Comparative study of Proportional Integral and Backstepping controller for Buck converter," in Electrical and Computer Technology, 2011. ICETECT 2011. International Conference on Emerging Trends, pp. 375-379, 2011.

[19] N. Mutoh, M. Ohno and T. Inoue, "A Method for MPPT Control While Searching for Parameters Corresponding to Weather Conditions for PV Generation Systems," IEEE Transactions on Industrial Electronics, vol. 53, pp. 1055-1065, Aug 2006.

[20] Se-Kyo Chung, "A phase tracking system for three phase utility interface inverters," IEEE Transactions on Power Electronics, vol. 15, pp. 431-438, May 2000.

\title{
BIOGRAPHIES OF AUTHORS
}

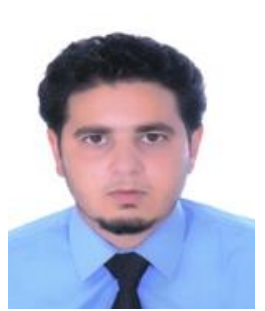

Mohammed El Malah was born in Morocco on November 02, 1980. He received the Master in Automatic, Signal Processing and Industrial Computing from Science and Technical Faculty, Hassan 1st University, Settat, Morocco in 2015. His research consists in the control of the linear and nonlinear systems with use of the advanced controller. Currently, he is preparing his $\mathrm{PhD}$ titled "Nonlinear control of renewable energy generation systems" in the Laboratory of System Analysis and Information Processing at Hassan 1stUniversity.

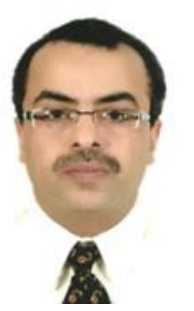

\begin{abstract}
Abdellfattah Ba-razzouk received the Master's degree (M.Sc.A.) in industrial electronics from the Université du Québec à Trois-Rivières (UQTR), Quebec, Canada, in 1993, and the Ph.D. degree in electrical and computer engineering from the École Polytechnique de Montréal, Quebec, Canada, in 1998. From 1997 to 2003, he was a Lecturer in "motors modelling and control" at the Department of Electrical and Computer Engineering, UQTR. In September 1998, he joined the Hydro-Quebec Industrial Research Chair on Power and Electrical Energy, UQTR, where he has been a Professional Research Scientist working on "high-performance intelligent control of electrical drives". Since June 2009, he is a Professor in electrical engineering with the Department of Applied Physics and a Researcher affiliated to "Systems Analysis and Information Processing Laboratory", both at the Faculté des Sciences et Techniques, Université Hassan 1er of Settat, Morocco. His research interests include high performance control of adjustable speed drives, parameter identification and adaptive control of electrical motors, neural networks, real-time embedded control systems, renewable energy systems, modelling and computer aided design, and real-time simulation of power electronics systems using multiprocessors platforms.
\end{abstract}



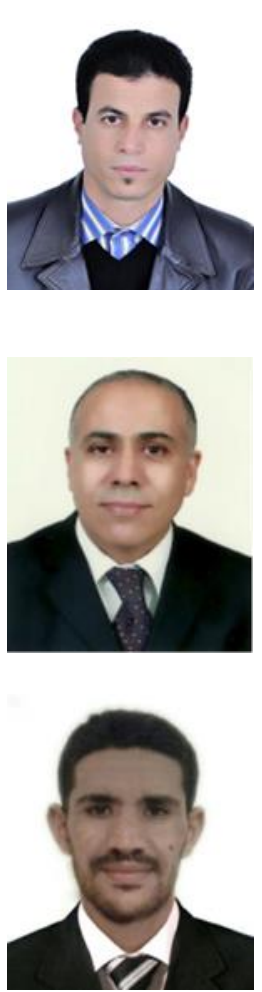

M'hammed Guisser received the $\mathrm{PhD}$ in engineering science "Automatic and Industrial Computing" in 2009 from the "Higher National School of Electricity and Mechanics (ENSEM)", University Hassan II, Casablanca, Morocco. His research interests include nonlinear control and state observer theory, robust and adaptive control, digital controller/observer and signal processing. He is involved in applications of these techniques to the control of unmanned aerial vehicles UAV, robotic systems and control of renewable energy. Currently, he is Assistant Professor in the Electrical Engineering Department of the "Centre Régional des Métiers de l'Education et de la Formation" (CRMEF), Settat, Morocco, and researcher in Laboratory ASTI, FST, Settat, University Hassan I Morocco.

Elhassane Abdelmounim received his $\mathrm{PhD}$ in applied Spectral analysis from Limoges University at science and technical Faculty, France in 1994. In 1996, he joined, as Professor, the applied physics department of the science and technical faculty of Hassan 1st University, Settat, Morocco. His current research interests include digital signal processing and machine learning. $\mathrm{He}$ is currently coordinator of a Bachelor of Science in electrical engineering and researcher in "ASTI" System Analysis and Information Technology Laboratory at science and technical faculty, Hassan 1st University, Settat, Morocco.

Mhamed Madark was born in Settat, Morrocco, in 1987. He is a Ph.D. student. He received his B.Sc. degree in mathematics engineering from the Science and Technical Faculty of Hassan 1st University, Settat, Morocco, in 2013, the M.Sc. degree in Automatic, Signal Processing and Industrial Computing from the Science and Technical Faculty of Hassan 1st University, Settat, Morocco, in 2015. His research interests include the adaptive robust nonlinear control of the induction machine and robust nonlinear controller design for three phase grid connected PV systems. 